\title{
Pierre-Marc de Biasi, Gustave Flaubert, une manière spéciale de vivre
}

Ida Merello

\section{Q OpenEdition \\ 1 Journals}

\section{Edizione digitale}

URL: http://journals.openedition.org/studifrancesi/6981

DOI: 10.4000/studifrancesi.6981

ISSN: 2421-5856

\section{Editore}

Rosenberg \& Sellier

\section{Edizione cartacea}

Data di pubblicazione: 1 septembre 2010

Paginazione: 395

ISSN: 0039-2944

\section{Notizia bibliografica digitale}

Ida Merello, «Pierre-Marc de Biasi, Gustave Flaubert, une manière spéciale de vivre», Studi Francesi [Online], 161 (LIV | II) | 2010, online dal 30 novembre 2015, consultato il 11 janvier 2021. URL: http:// journals.openedition.org/studifrancesi/6981; DOI: https://doi.org/10.4000/studifrancesi.6981

Questo documento è stato generato automaticamente il 11 janvier 2021.

\section{(c) (i) (9)}

Studi Francesi è distribuita con Licenza Creative Commons Attribuzione - Non commerciale - Non opere derivate 4.0 Internazionale. 


\title{
Pierre-Marc de Biasi, Gustave Flaubert, une manière spéciale de vivre
}

\author{
Ida Merello
}

\section{NOTIZIA}

PIERRE-MARC DE BIASI, Gustave Flaubert, une manière spéciale de vivre, Paris, Grasset \&

Fasquelle, 2009, pp. 494.

Dopo un corpo a corpo con Flaubert che prosegue da più di un ventennio, l'A. ci propone qui una minuziosa ricostruzione della vita e dell'opera dello scrittore, nella sua globalità, in appassionata polemica con L'idiot de la famille di Sartre, per segnalare fin dalle prime prove - siano pure l'ascolto delle leggende della bonne, o dei racconti di père Mignot, o la lettera a Ernest Chevalier - i primi "sintomi" della sua genialità. La lunga frequentazione, da parte dell'A., dell'opera, dei brouillons, della corrispondenza, sboccia qui in un atto d'amore, che entra nelle più minute pieghe del vissuto: la sua prima scommessa è quella di procedere poi in un andirivieni continuo tra l'uomo e la sua produzione letteraria, agendo quindi in contrasto con gli assunti stessi dello scrittore più impersonale del secolo, che rifiuta ogni coinvolgimento del proprio punto di vista nell'atto della narrazione. Così, dopo aver fissato con precisione ogni dettaglio della vita, l'A segnala ad esempio quante volte un episodio del vissuto, diventato simbolicamente significativo per Flaubert, viene ripetuto in diverse declinazioni nella scrittura. La definizione che l'A. applica a Flaubert («écrivain chercheur», che propone una continua «remise en cause esthétique du concept de vérité»), può ugualmente bene essere applicata a lui stesso, in quanto propone una continua «remise en cause » del senso dell'opera attraverso continue modificazioni del punto di vista. Il libro si propone con evidenza come un compendio flaubertiano ormai «incontournable». 